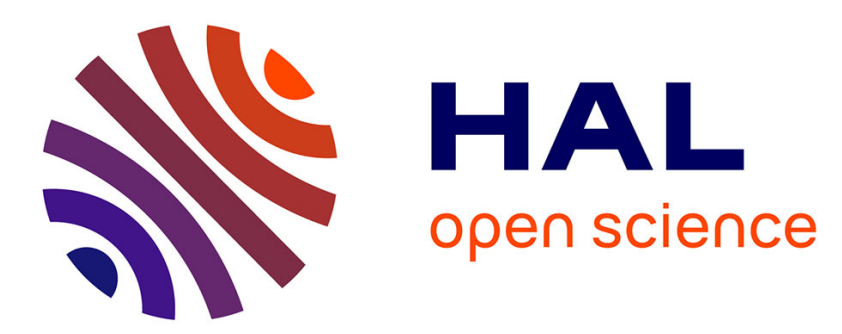

\title{
Nanoindentation in teeth: the influence of experimental conditions on local mechanical properties
}

Griselda María Guidoni, Julia Denkmayr, Thomas Schöberl, Ingomar Jäger

\section{To cite this version:}

Griselda María Guidoni, Julia Denkmayr, Thomas Schöberl, Ingomar Jäger. Nanoindentation in teeth: the influence of experimental conditions on local mechanical properties. Philosophical Magazine, 2006, 86 (33-35), pp.5705-5714. 10.1080/14786430600599757 . hal-00513665

\section{HAL Id: hal-00513665 \\ https://hal.science/hal-00513665}

Submitted on 1 Sep 2010

HAL is a multi-disciplinary open access archive for the deposit and dissemination of scientific research documents, whether they are published or not. The documents may come from teaching and research institutions in France or abroad, or from public or private research centers.
L'archive ouverte pluridisciplinaire HAL, est destinée au dépôt et à la diffusion de documents scientifiques de niveau recherche, publiés ou non, émanant des établissements d'enseignement et de recherche français ou étrangers, des laboratoires publics ou privés. 


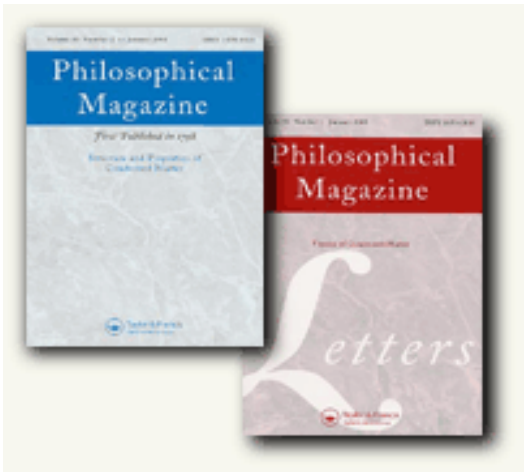

\section{Nanoindentation in teeth: the influence of experimental conditions on local mechanical properties}

\begin{tabular}{|r|l|}
\hline Journal: & Philosophical Magazine \& Philosophical Magazine Letters \\
\hline Manuscript ID: & TPHM-05-Oct-0467 \\
\hline Journal Selection: & Philosophical Magazine \\
\hline Date Submitted by the & 28-Oct-2005 \\
\hline Complete List of Authors: & $\begin{array}{l}\text { GUIDONI, Griselda; Montanuniversität Leoben, Department } \\
\text { Materialphysik } \\
\text { DENKMAYR, Julia; Montanuniversität Leoben, Department } \\
\text { Materialphysik } \\
\text { Schöberl, Thomas; Montanuniversität Leoben, Department } \\
\text { Materialphysik; Austrian Academy of Sciences, Erich Schmid } \\
\text { Institute for Material Sciences } \\
\text { JÄGER, Ingomar; Montanuniversität Leoben, Department } \\
\text { Materialphysik }\end{array}$ \\
\hline Keywords: & nanoindentation, biological materials \\
\hline Keywords (user supplied): & \begin{tabular}{l} 
intertubular dentin, experimental conditions, Hank \\
\hline
\end{tabular} \\
\hline
\end{tabular}

\section{S) ScholaroNE \\ Manuscript Central}




\title{
Nanoindentation in teeth: the influence of experimental conditions on local mechanical properties
}

\author{
G. GUIDONI*†, J. DENKMAYR+; T. SCHÖBERLA§ and I. JÄGER $\diamond$. \\ †Department Materialphysik, Montanuniversität Leoben. Jahnstrasse 12, A- \\ 8700, Leoben, AUSTRIA. Tel.: + 43 (0) 3842804 215. Fax: + 43 (0) 3842804 \\ 116. Griselda.Guidoni@notes.unileoben.ac.at \\ +Department Materialphysik, Montanuniversität Leoben. Jahnstrasse 12, A- \\ 8700, Leoben, AUSTRIA. Tel.: + 43 (0) 3842804 215. Fax: + 43 (0) 3842804 \\ 116. \\ A Department Materialphysik, Montanuniversität Leoben. Jahnstrasse 12 , A- \\ 8700, Leoben, AUSTRIA. Tel.: + 43 (0) 3842804 304. Fax: + 43 (0) 3842804. \\ Schoeber@unileoben.ac.at \\ $\S$ Erich Schmid Institute for Material Sciences, Austrian Academy of Sciences. \\ Jahnstrasse 12, A-8700, Leoben, Austria. Tel.: + 43 (0) 3842804 304. Fax: + \\ 43 (0) 3842 804. Schoeber@unileoben.ac.at \\ $\diamond$ Department Materialphysik, Montanuniversität Leoben. Jahnstrasse $12, \mathrm{~A}-$ \\ 8700, Leoben, AUSTRIA. Tel.: + 43 (0) 3842804 308. Fax: + 43 (0) 3842804 \\ 116. Ingomar@unileoben.ac.at
}

\begin{abstract}
The influence of various experimental conditions on the elastic modulus and hardness of human intertubular dentin was studied using instrumented nanoindentation at room temperature. The conditions studied were: dry (chemically dehydrated) versus wet (prepared and nanoindented under HBSS), the influence of long-term storage under HBSS at ca. $4^{\circ} \mathrm{C}$, and the influence of deep-freezing under dry and wet conditions, respectively. The reversibility of chemical dehydration and the consequences of multiple deep-freezing cycles were also investigated. Two premolars of a twelve-years-old human male were chosen for evaluation. The absolute values of the mechanical properties differed by a factor of $\sim 2$ and $\sim 3$ between dry and wet state, whereas trends were conserved. Deep-freezing wet dentin samples deteriorated their mechanical properties by about 20 to $28 \%$, whereas dehydrated samples suffered no damage. This may be due to the mechanical damage by the volume increase of water freezing inside the tubules.
\end{abstract}

Keywords: nanoindentation, biological materials, intertubular dentin, experimental conditions, Hank's balanced salt solution (HBSS).

\section{INTRODUCTION}


Storing teeth is an important matter concerning dental medicine. Keeping the integrity of these materials for further transplantation, replantation and restoration is an important issue for successful dental treatments $[1,2]$ In addition, in the case of research investigations, it is a crucial factor in order to measure the real mechanical response of such materials in a state as close to in-vivo as possible. Biological samples not studied immediately after harvesting, are usually stored in the laboratories until testing. Several storage solutions have been reported (HBSS; $\mathrm{CaCl}_{2}$ solutions, water, etc) in order to simulate in vivo conditions and to try to keep the integrity of the teeth. However, these solutions can strongly influence the native properties of these systems $[3,4$, etc]

Nanoindentation is a technique able to detect the above deviations in the local mechanical properties of these materials, as Habelitz et al. [5] also demonstrated with three different storage solutions. Although the penetration depth of nanoindentation is small $(<1 \mu \mathrm{m})$; the mechanical properties thus obtained are assumed to be representative of the whole sample and are comparable to one of the most accurate ways of determining elastic constants of a material, i.e. sonic measurements [6]. Nanoindentation is a versatile, powerful and highly suitable technique for testing biomaterials, mainly because there is no need of vacuum condition and near in vivo condition can be attained quite easily.

Dentin is a mineralized tissue, containing approximately $50 \%$ vol. mineral and $30 \%$ vol. of collagen fibrils. Dentin contains many tubules typically radiating outwards from the root cavity, in which the dentinal fluid is located and the cytoplasmic processes of the cells that have formed the dentin, the odontoblasts, take place. In addition, tubules are surrounded by a thin, hard, highly mineralized shell of peritubular dentin, the contribution of which to the overall mechanical properties of a tooth is not yet quite clear [7 - 9]. Local mechanical properties of the intertubular dentin (between the tubules) investigated here depend on mineral content and level of interpeptide hydrogen bonding. Most storage solutions are known to alter both characteristics $[5,10]$.

The present study investigates the difference in hardness and elastic stiffness between dehydrated samples and samples prepared and indented under HBSS. Furthermore the influence of the temperature of storage on the measured local mechanical properties is studied, since Panigh et al. [11] found an influence, albeit for the case of bond strength. The reversibility of chemical dehydration is tested, carrying out nanoindentations in the same sample first in wet and then in dried plus rewetted conditions. In addition the suitability of HBSS for longterm storing of teeth is studied by testing one premolar of the same human individual immediately after extraction, and another one after two years of storage in HBSS (plus Na-azid).

The method of nanoindentation is carried out on intertubular dentin after storing the corresponding samples from the same tooth under four different 
conditions: immersed in HBSS and room temperature, chemically dehydrated and room temperature, immersed in HBSS and deep frozen, and chemically dehydrated and deep frozen. Correspondingly, nanoindentations are done under atmospheric and fluid environments as appropriate.

\section{SAMPLE PREPARATION}

Preliminary experiments with a human tooth of unknown origin extracted at hospital ended with a thick, very soft surface layer of unknown composition in spite of the use of antibacterial agent and had to be discarded. Another investigated tooth had to be discarded because it had been cut in halves during extraction, which presumably lead to damage due to overheating. These facts prove that in order to get reliable values of mechanical properties of teeth it is of utmost importance to use healthy, freshly erupted specimens, extracted by a dental surgeon fully aware of the requirements of the experiments and thus avoiding predamage.

For the investigation reported here two second healthy premolars extracted from a 12 years old human male were examined. Each of them was extracted from each side of the jaw as part of an orthodontical treatment due to a lack of alveolar arch space distal to the second molar.

One of two premolars was mechanically tested immediately after extraction (1P) and the second one (2P) was studied after 2 years of storage immersed in HBSS and kept at $\sim 4^{\circ} \mathrm{C}$.

The samples were cut with a diamond saw in two (1P) and four sections (2P) along the crown-root direction, carefully avoiding any overheating. Half of the samples of the same premolar were immediately dehydrated ('DEH'), soaking it in different ethanol grading; the remainders were immersed in HBSS ('HBSS'). In addition, the influence of two temperatures of storage were studied, in the case of $2 \mathrm{P}$ samples: room temperature and $-15^{\circ} \mathrm{C}$ (deep freezing), in combination with the 'DEH' and 'HBSS' condition described above.

After the indentation of the (2P) samples treated according to the first experimental conditions, the former dehydrated samples were rewetted (RW) in HBSS and stored at the same temperature as at the beginning (RT or $-15^{\circ} \mathrm{C}$ ) and the former HBSS samples were dehydrated ('DEH') in ethanol and stored at the same temperature as in the beginning. The later experiments were done to study the reversibility of chemical dehydration. In addition, one ('HBSS') sample was frozen and thawed 5 times (5x) to investigate the occurrence or not of additional damage with multiple freezing, on the local mechanical properties measured at room temperature.

For better understanding, all the conditions tested, including the nomenclature used, are summarized in table 1.

'[Insert table 1 about here]' 
For testing and handling purposes, some of the pieces were simply glued to a platform with cyanacrylate glue and some of them were embedded in a polymer resin. In all the cases, the transversal section of the premolar consisting of enamel, dentin and pulp, was accessible for preparation. The exposed area was ground and polished to a $2500 \mathrm{P}$ grit finish with silicon carbide cloths, followed by polishing in $0.3 \mu \mathrm{m}$ alumina suspension. In the case of 'wet' conditions, the samples were permanently rinsed with HBSS while polishing, and stored under HBSS all the time to avoid accidental dehydration. This is essential especially in the last stages of preparation.

\section{NANOINDENTATION TESTS}

Nanoindentation tests were carried out using an add-on nanoindentation device (Hysitron Triboscope, Hysitron Inc., Minneapolis, MN, USA) mounted on the scanner head of an AFM stage (Veeco - Digital Instruments, Santa Barbara, CA, USA).

Two kinds of configurations were used in the nanoindenter: on the one hand, 'dry indentations', in which the dehydrated samples were indented under atmospheric conditions with a cube-corner indenter, on the other hand, 'wet indentations', in which sample and part of the indenter were immersed in HBSS during testing. For the latter case the conical indenter tip is mounted at the end of a tungsten rod ca. $9.5 \mathrm{~mm}$ long in order to keep the transducer well away from the fluid cell. Unfortunately, it turned out that the long rod sometimes introduced a markedly higher level of noise into the measurements; therefore we preferred the standard tip with the standard short rod for the "dry" measurements. No remarkable influence, on the other hand, was found of the fluid itself on the results. So, all the 'wet' indentations were done with the same conical indenter on a long tungsten rod, whereas all the 'dry' indentations were done with the same cube corner indenter. This procedure is justified by a preliminary investigation [12] showing that the shape of the indenter does not influence the results of $\mathrm{H}$ and $\mathrm{E}$ in dentin (results not shown here).

Nanoindentation tests were carried out in several loading-unloading steps, the first three steps were the same for (1P) and (2P) samples: first the specimen was linearly loaded to the maximum load in 5 seconds, secondly the load was maintained 50 seconds in order to eliminate most of the creep before unloading, thirdly the sample was unloaded to an intermediate load. In the case of $1 \mathrm{P}$ specimens and wet condition, after the third step, 5 cycles of unloading and loading between $10 \%$ of maximum load and maximum load were included and for each indentation, 5 elastic moduli were calculated from the unloading curves and averaged. Hardness was calculated from the first cycle. Since measurements from 1P samples showed no significant difference between $E$ calculated from the five unloading curves, these cycles were not applied to the $2 \mathrm{P}$ samples. Regarding (2P) samples, the third unloading step was done until an intermediate load of $100 \mu \mathrm{N}$ within $10 \mathrm{~s}$, fourth step was to hold this load $20 \mathrm{~s}$ for control of thermal drift and, finally, unloading linearly to zero within $2 \mathrm{~s}$. 
Maximum load was $5000 \mu \mathrm{N}$ in all the samples and conditions, except in the case of the 'dry' indentations of $2 \mathrm{P}$ samples, were maximum load was $2500 \mu \mathrm{N}$, in order to keep the penetration depth between 700 and $800 \mathrm{~nm}$.

The temperature of testing was in all the cases room temperature. The samples stored in a deep-frozen $\left(-15^{\circ} \mathrm{C}\right)$ condition were defrosted before testing.

In the case of $1 \mathrm{P}$ specimens, the indentations were done along a line starting in the dentin-enamel junction (DEJ) and finishing in the root, far away from the pulp. On the other hand, in the case of $2 \mathrm{P}$ samples, the indentations were done randomly in the dentin zone, far away from the pulp and enamel. In the later, the tests were repeated daily during two weeks in order to check the stability of the measured mechanical properties with time. In both cases, the indented region was intertubular dentin, and the indents were carefully placed by means of the AFM mode scanning with the nanoindenter tip between the tubules to avoid any influence of the peritubular dentin and/or tubules on the results.

Elastic Modulus and Hardness were calculated by means of the loaddisplacements curves using the well known Oliver-Pharr method [13].

At least 30 measurements per storage condition were taken. In order to compare the results, ANOVA one way statistical analysis was used, with a confidence interval of 0.05 .

\section{RESULTS}

The ratio between the measured mechanical properties, $\mathrm{E}$ and $\mathrm{H}$, in the wet and dry state is $\sim 2$ and $\sim 3$, respectively, as can be seen from figure 1 a and figure $1 \mathrm{~b}$. However, although the absolute values of $\mathrm{E}$ and $\mathrm{H}$ differ, the trends, such as the typical gradient in $\mathrm{E}$ and $\mathrm{H}$ starting at the dentin-enamel-junction (DEJ) and extending for some hundreds of micrometers into the dentin are conserved, as shown in figure $2 \mathrm{a}$ and figure $2 \mathrm{~b}$. In addition a few indentations were made in the enamel, showing that even in this very highly mineralized material (up to $95 \mathrm{wt} \%,[14,15]$ ) a strong difference in the hardness exists between the dry and the wet state $(\approx 2: 1)$, whereas, strange enough, the elastic modulus remains unaltered. But since enamel was not the main aim of this investigation, this was not pursued further.

\section{'[Insert figure $1 \mathrm{a}$ and figure $2 \mathrm{~b}$ about here $]^{\prime}$ \\ '[Insert figure $2 \mathrm{a}$ and figure $2 \mathrm{~b}$ about here]'}

The measured mechanical properties in the case of $2 \mathrm{P}$ samples for each condition were significantly similar during the two weeks of testing. For this reason, all the presented results correspond to the average of the measurements (among 30 to 180 nanoindentations per condition) during the evaluated time. 
The final median (average) data of all the initial conditions are shown in table 2 , followed by their standard deviation.

\section{'[Insert table 2 about here]'}

A result to point out is the similarity in the mechanical response of the $1 \mathrm{P}$ and 2P samples (denoted by dark and light grey cells for the corresponding wet and dry properties, respectively, in table 2), where the main difference is the storage time (immediately tested and stored during 2 years in HBSS, respectively).

As shown in table 2, for the $2 \mathrm{P}$ samples, the measured mechanical properties vary with the temperature of storage by $25 \%$, approx. in the case of wet conditions. This result was not observed in the dry conditions. From now, dry conditions will be denoted by simply ' $\mathrm{DEH}$ ' (without specifying temperatures of storage) since $\mathrm{E}$ and $\mathrm{H}$ are not influenced by the temperature of storage in the dry state.

Figure $3 \mathrm{a}$ and figure $3 \mathrm{~b}$ show all the results of the wet and rewetted conditions of 2P samples. Independently of the storage conditions in the dehydrated state, after rewetting, their mechanical properties fit in with the mechanical properties of HBSS RT condition. A similar behaviour is found in the case of the redehydrated sample at RT, which mechanical response agrees with the response of the native dehydrated samples ('DEH'): $21.67 \pm 0.67 \mathrm{GPa}$ and $0.95 \pm 0.03$ $\mathrm{GPa}$ for $\mathrm{E}$ and $\mathrm{H}$, respectively (Refer to table 2 for comparison). In the case of frozen and defrosted several times, there is no observable extra damage in the mechanical properties after the first cycle, as it can also be seen in figure $3 a$ and $3 b$.

'[Insert figure $3 a$ and figure 3b about here]'

\section{DISCUSSION}

It is well known that the fluid for storing dental tissues can alter their mechanical properties $[5,10]$. Alcohol, e.g. produces shrinkage of the tissue because it increases the levels of interpeptide hydrogen bonding [10]. This leads to enhanced hardness and mechanical stiffness, compared with the case of storage in HBSS. HBSS, on the other hand, has a major percentage of water, with the necessary ions to prevent dentin demineralization $[5,10]$ and water plasticizes collagen by breaking interpeptide bonds [5], which is translated into lowered hardness and stiffness of the hydrated samples. As the results show, the difference is remarkable: $\mathrm{E}$ and $\mathrm{H}$ decrease to about half and one third of their values, respectively, on going from dry (alcohol) to wet (HBSS) conditions. Nevertheless, the fluid influences all the tooth structure and the tendencies like, e.g. local gradients, are kept even though the absolutes values differ considerably. 
The fact that the mechanical properties were kept even after two years of storage in HBSS, supports the result presented by Habelitz et al. [5] that HBSS is a most suitable solution for storing teeth. However, in this study it was found that it is not only suitable for short periods (two weeks) as they stated, but also for longer ones (years).

In addition to the effects of different storing fluids discussed above, it was observed in this work that the temperature of storage is also important. HBSS is an aqueous buffer solution. Water is mainly located inside the tubules, so when the samples are deep frozen, the increase in volume of frozen water may introduce irreversible mechanical damage in the microstructure of the dentin tubules as well as in the surrounding dentin. This may explain the $25 \%$ decrease in local mechanical properties obtained among the samples stored submersed under HBSS and kept at room temperature and the ones deep frozen, respectively. However, this phenomenon is not observed in chemically dehydrated samples because the water is replaced by alcohol, which at $-15^{\circ} \mathrm{C}$ neither freezes nor experiences any volume increase. In contrast to our findings, Moscovicha et al. [5] did not observe changes in the hardness of dentin after storing it at $-18^{\circ} \mathrm{C}$ in water. However, their chosen method was macroindentations with loads of $30 \mathrm{~kg}$ in $2.1 \mathrm{~mm}$ thick disks, which may have hidden the microstructural changes introduced by the swelling of solidified water since due to the average size of the macroindentations, it averages the contributions of peritubular, intertubular dentin and tubules, and judging by the load used and specimen thickness its results may be influenced by the sample holder too. Nanoindentation, on the other hand, is a powerful technique to investigate biomaterials with hierarchical structure, because nanoindentation is capable to measure mechanical properties in the micrometer range, allowing researchers to understand and discriminate the influence of micrometer size structures on the mechanical behaviour.

After dehydrating the former wet samples and rewetting the former dehydrated samples, the measured local mechanical properties corresponded to the initially dehydrated and wet samples, respectively. It is remarkable that, independently of the initial storing temperatures in the dehydrated state, the $E$ and $\mathrm{H}$ of the rewetted conditions fitted in with the measured properties of just wet and kept at room temperature ('HBSS RT Average', in figure 3a and figure 3b) samples. This is explained by the fact that initially, with the former dehydration process, the water is replaced by alcohol which does not freeze nor increase its volume. When again the ethanol is replaced by HBSS in the rewetting step, the resulting microstructure corresponds to the 'HBSS RT' condition since freezing the sample did not introduce any mechanical damage. This simple model explains why all the rewetted samples respond in a similar way as immersed in HBSS and kept at room temperature, independently of the temperature of storage in the dehydrated state.

The above observations indicate reversibility of chemical dehydration as already presented by Nalla et al. 5] for the fracture resistance behaviour of dentin. 


\section{CONCLUSIONS}

Nanoindentation is a valuable technique for studying biomaterials. Not only because vacuum environment is not a requirement, but also because near in vivo conditions are achievable allowing indentations to be done under fluids.

The several conditions investigated in this work led to the following conclusions: - The temperature of storage is an important factor for storing teeth in HBSS, if it reaches the solidification point of water. This conclusion may be extrapolated to all aqueous fluids which preserve dentin mineralization, because it is the increase in water volume after freezing which introduces irreversible damage.

- Chemical dehydration seems to be a reversible process.

- Hank's balanced salt solution (HBSS) is a suitable fluid for storing teeth.

- The mechanical properties of dehydrated dentin considerably differ from the near in vivo condition (immersed in HBSS). In this case, the plasticizing role of water and the presence of the necessary ions to prevent demineralization in HBSS are the reason for obtaining lower mechanical properties than in the dehydrated state, where alcohol is thought to increase the levels of polypeptide bonds with the expected increase in $E$ and $H$ that is entailed.

- Deep-freezing not only is not needed when using HBSS for storing teeth, but even detrimental.

- Healthy teeth are necessary to distinguish the mechanical response differences among different storing conditions.

\section{ACKNOWLEDGEMENTS}

Griselda Guidoni acknowledges the financial support provided by the European Community under contract P043-EU-01-02 Biomimetic Systems. The authors thank Dr. Erich Klein and his team for the prompt and very competent delivery of two perfect premolars for the investigation.

\section{REFERENCES}

[1] O. Schwartz, Int. J. Oral Maxillofac. Surg. 1530 (1986.

[2] H. Moscovich, N. H. J. Creugers, Journal of Dentistry 2621 (1998).

[3] M. B. Gustafson, R. B. Martin, V. Gibson, D. H Storms, S. M. Stover, J. Gibeling, L. Griffin, I. Biomechanics 291191 (1996).

[4] D. H. Pashley, K. A. Agee, R. M. Carvalho, K. Lee, F. R. Tay, T. Callison, Dental Materials 19347 (2003).

[5] J. H. Kinney, S. J. Marshall S. Habelitz, G. W. Marshall, M. Balooch, S. J. Marshall, J. Biomech. 35995 (2002). 
[6] J. H. Kinney, S. J. Marshall, G. W. Marshall, Crit. Rev. Oral Biol. Med. 14 $13(2003)$

[7] J. H. Kinney, M Balooch, S.J. Marshall, G. W. Marshall Jr., T. P. Weihs, Archs oral Biol. 419 (1996)

[8] G. Balooch, G. W. Marshall, S. J. Marshall, O. L. Warren, S. A. S. Asif and M. Balooch, J. Biomechanics 371223 (2004).

[9] J. H. Kinney, M. Balooch, G. W. Marshall, S. J. Marshall, Archs Oral Biol 44813 (1999).

[10] R. K. Nalla, M. Balooch, J. W Ager III, J. J. Kruzic, J. H. Kinney, R. O. Ritchie, Acta Biomateriala 131 (2005).

[11] M. M. Panigh, D. Allart, B. M Jacquots, J. Camps, C. G'Sell, Dent. Mater. 1356 (1997).

[12] W. Tesch, N. Eidelman, P. Roschger, F. Goldenberg, K. Klaushofer, P. Fratzl, Calcif. Tissue Int. 69147 (2001).

[13] W. C. Oliver, G. M. Pharr, J. Mater. Res., 71564 (1992).

[14] M. Barbour, D. M. Parker, K. D. Jandt, J. Colloid and interface Sci. 2659 (2003).

[15] M. Finke, J. Hughes, D. Parker, K. Jandt, Surface Sci. 456491 (2001).

[16] H. Moscovich, N. H. J. Creugers, J. A. Jansen, J. G. C. Wolke, Journal of Dentistry 27503 (1999). 


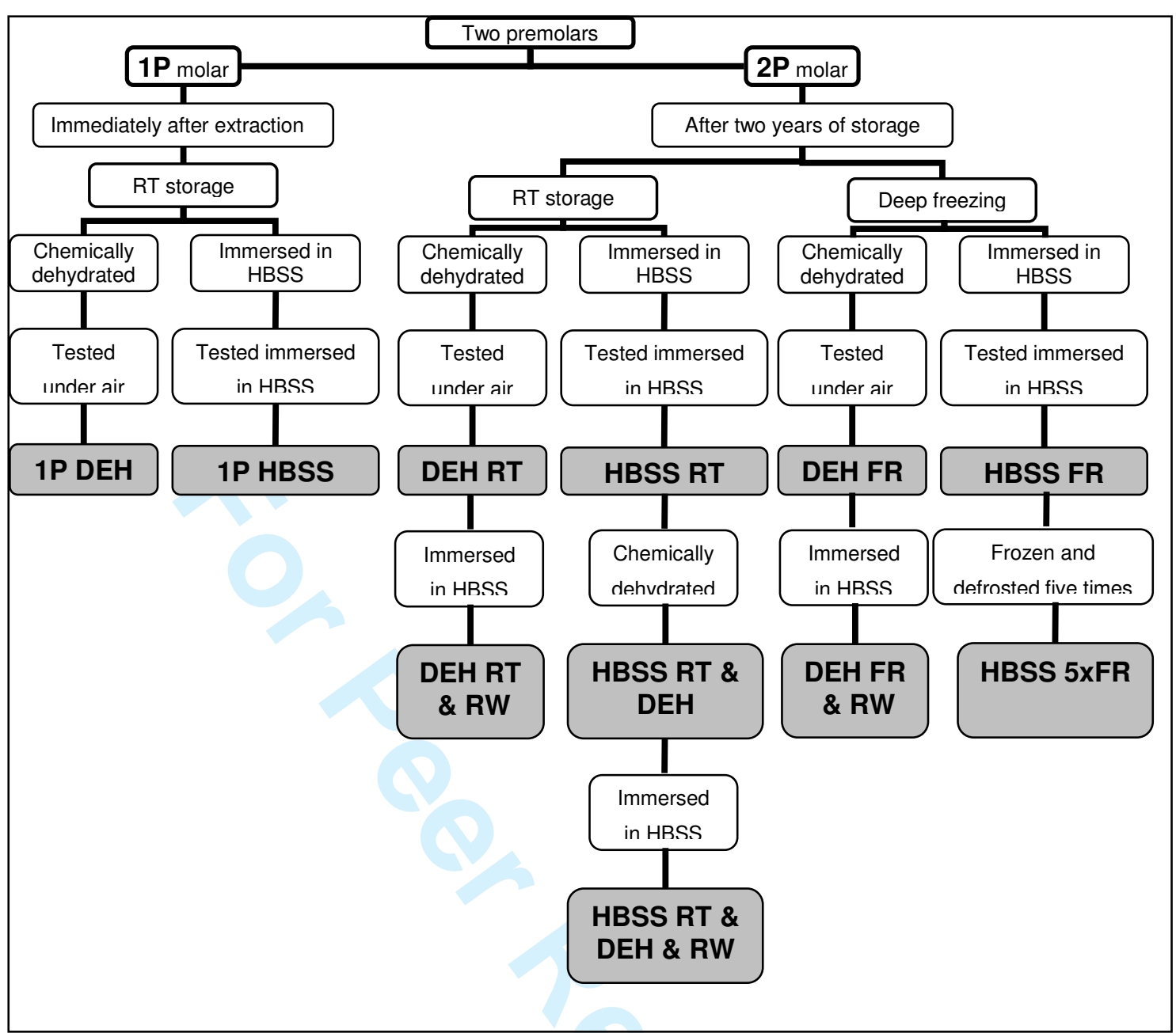




\section{ELASTIC MODULUS}

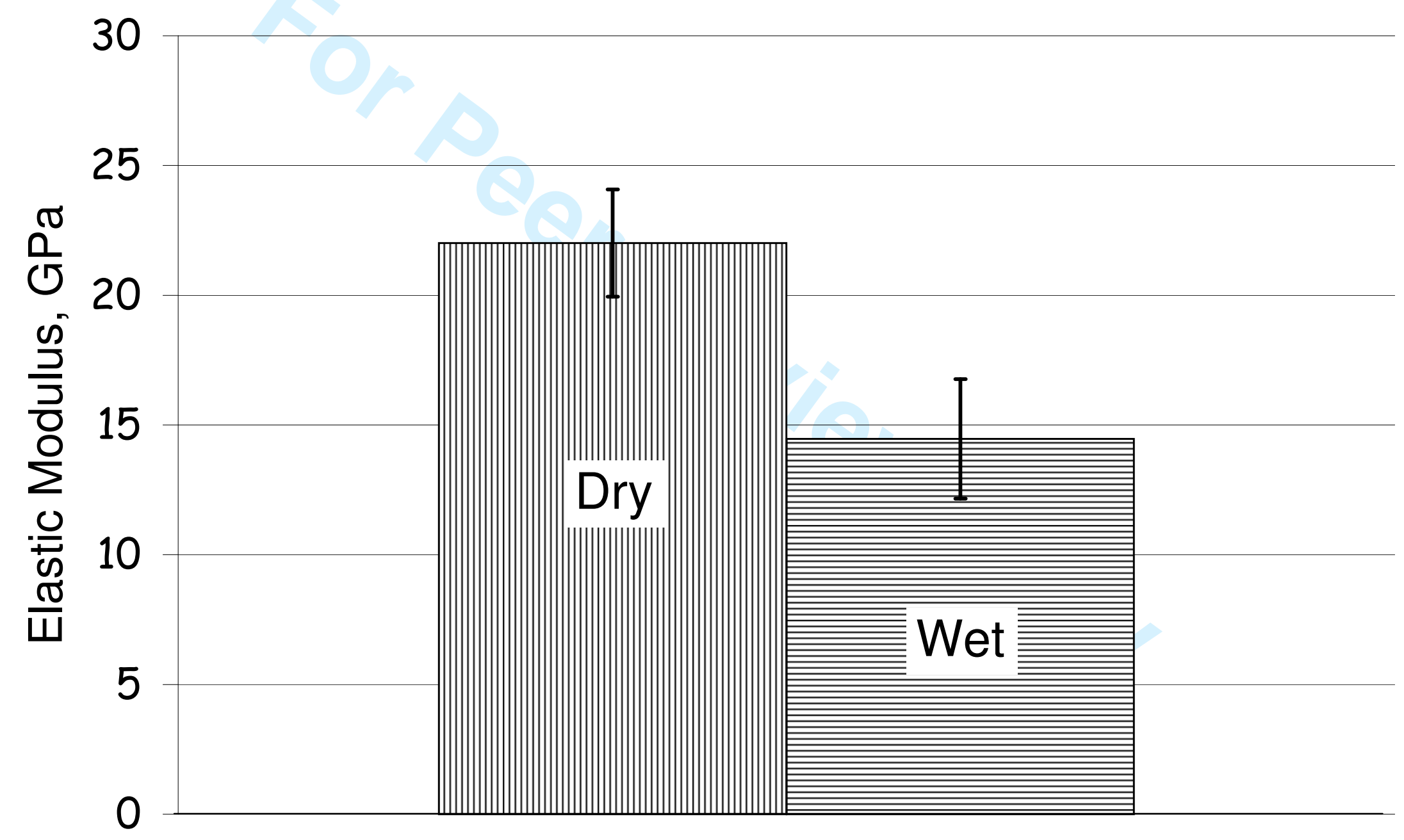




\section{HARDNESS}

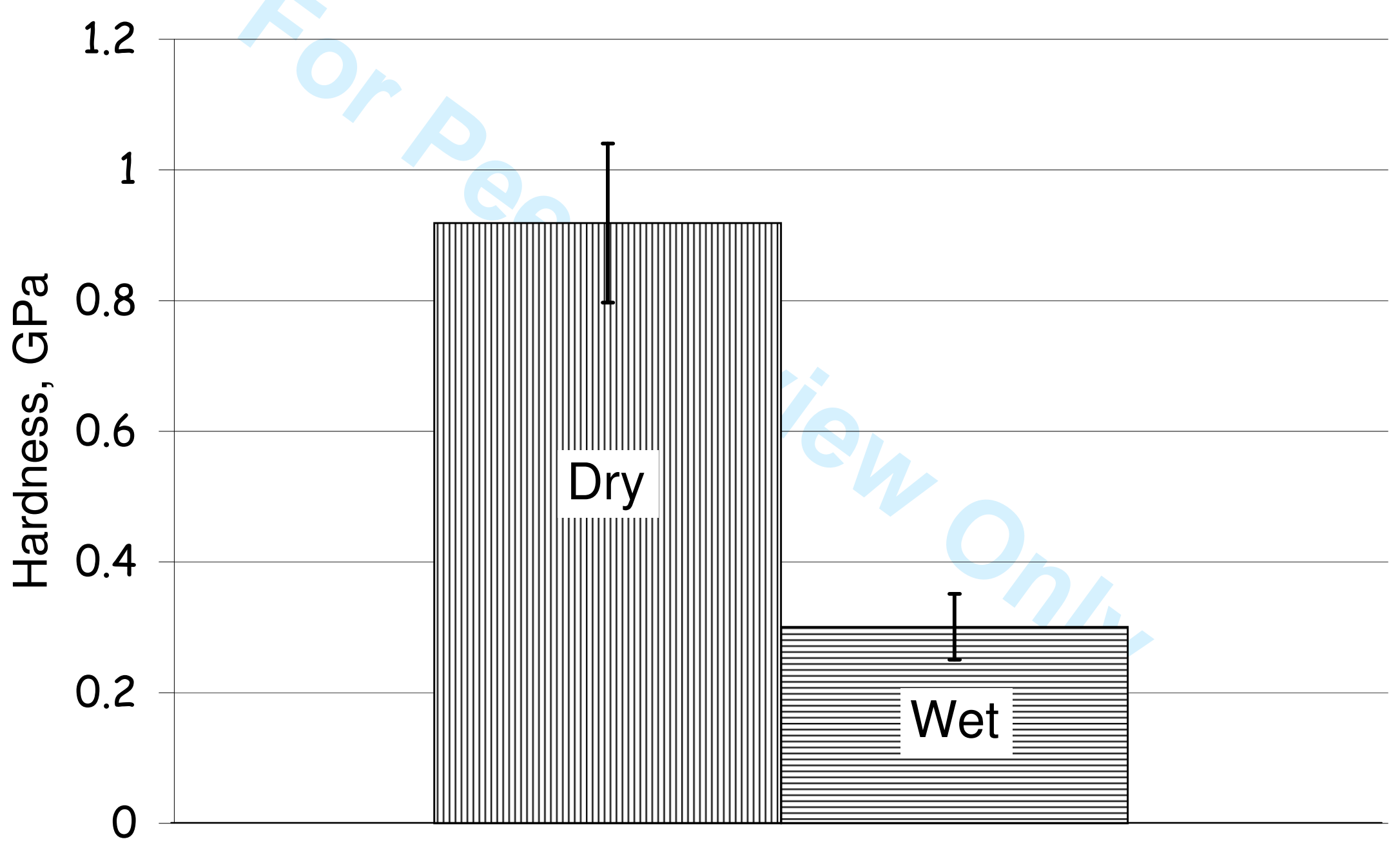




\section{ELASTIC MODULUS}

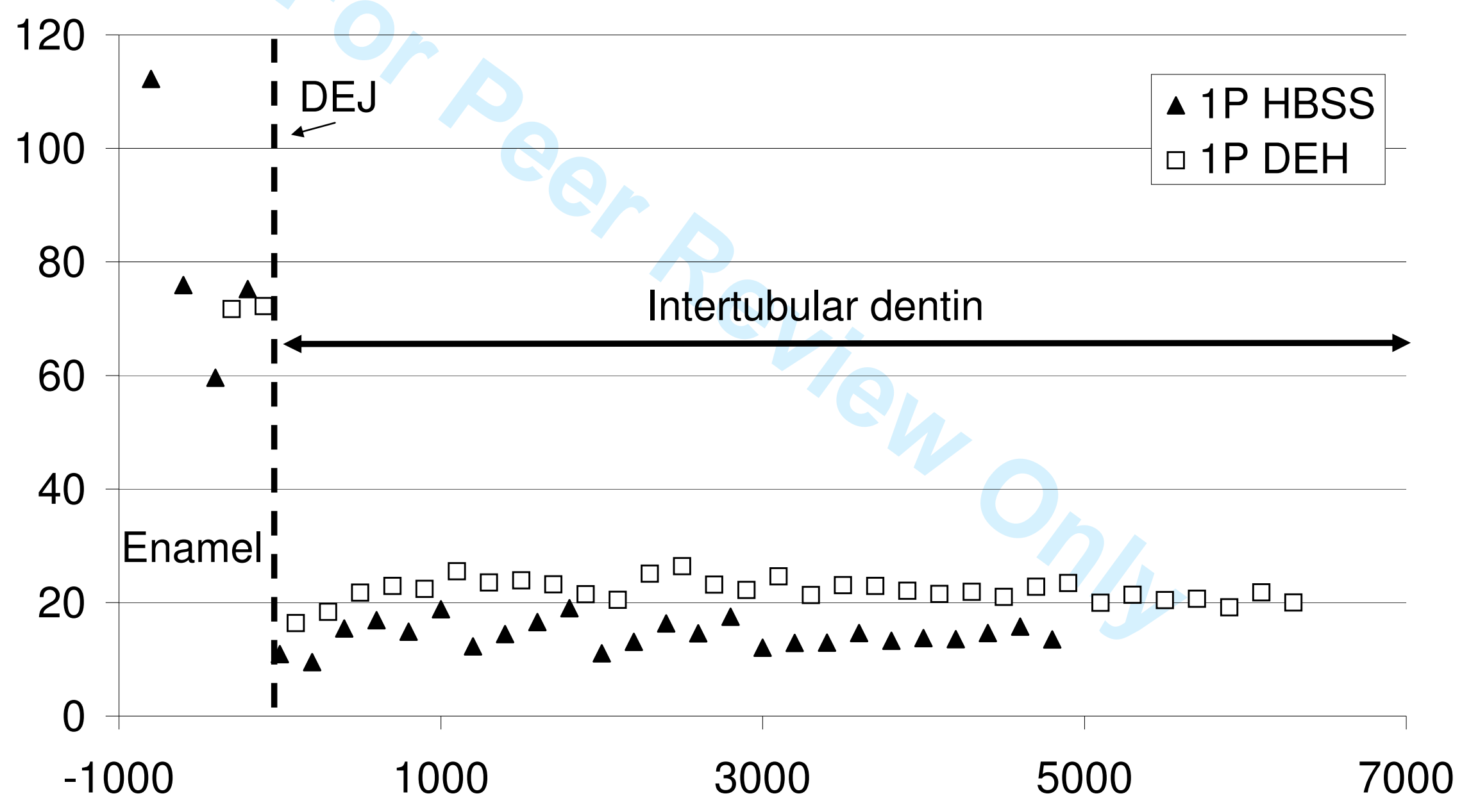




\section{HARDNESS}

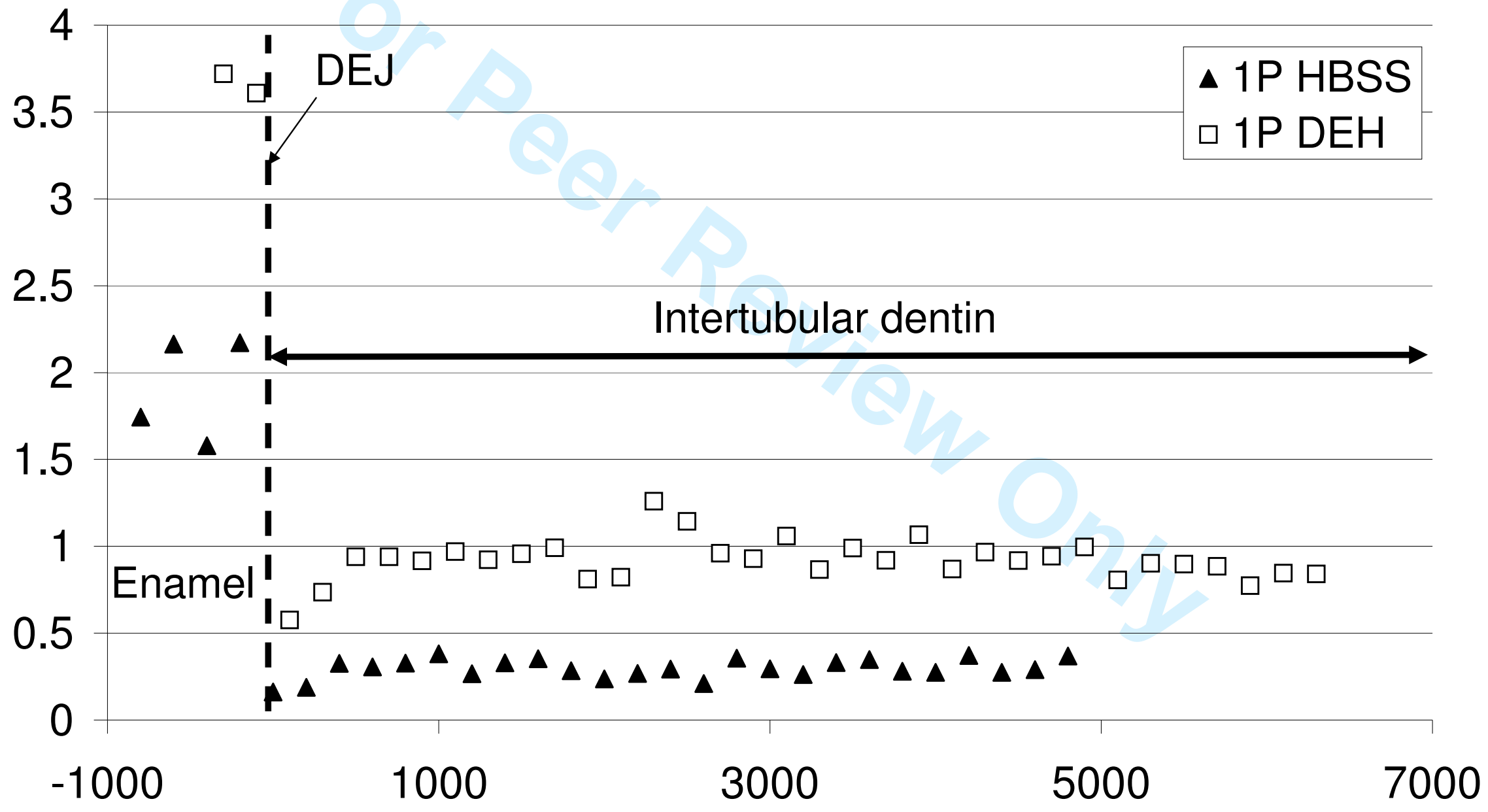




\section{ELASTIC MODULUS - WET}

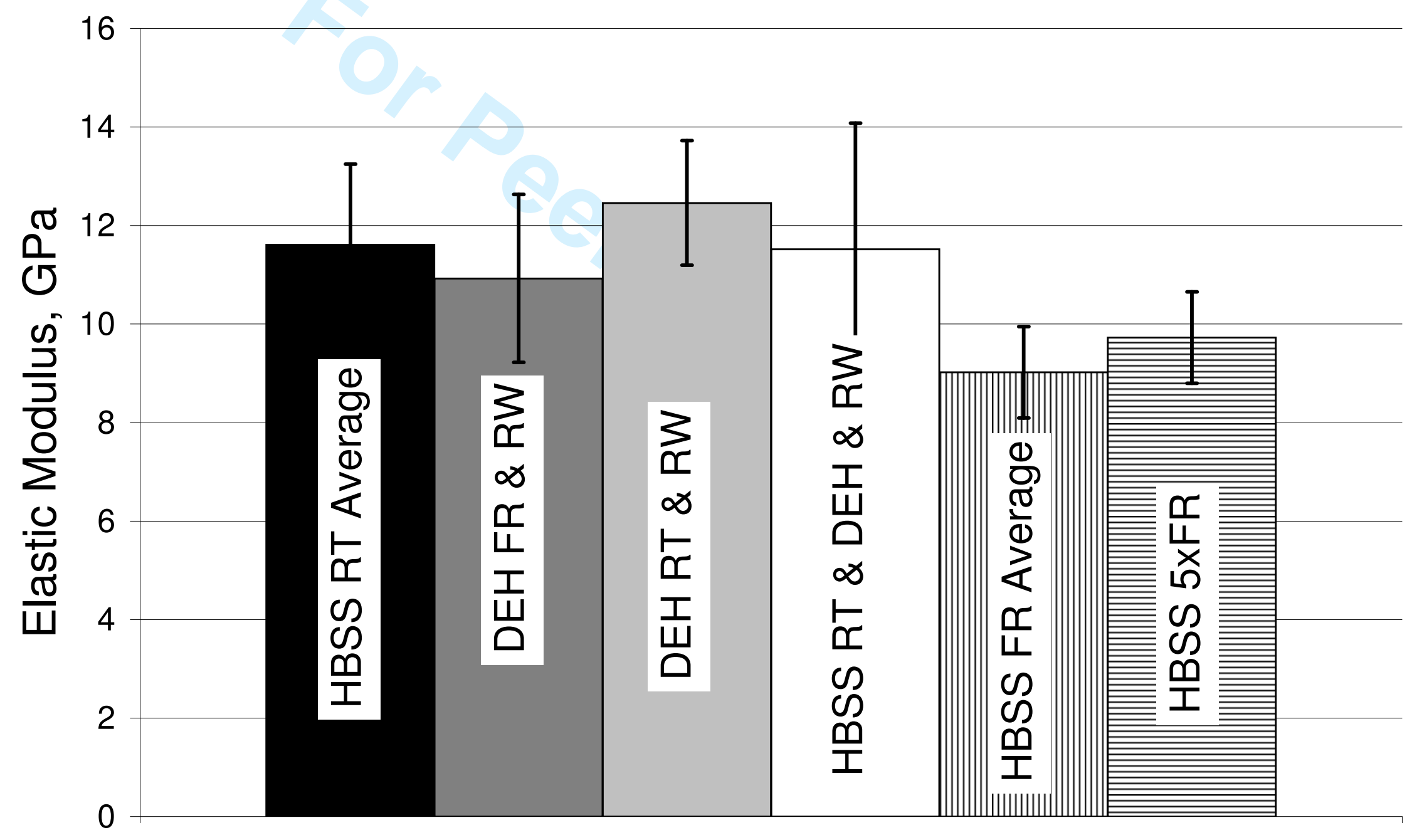




\section{HARDNESS - WET}

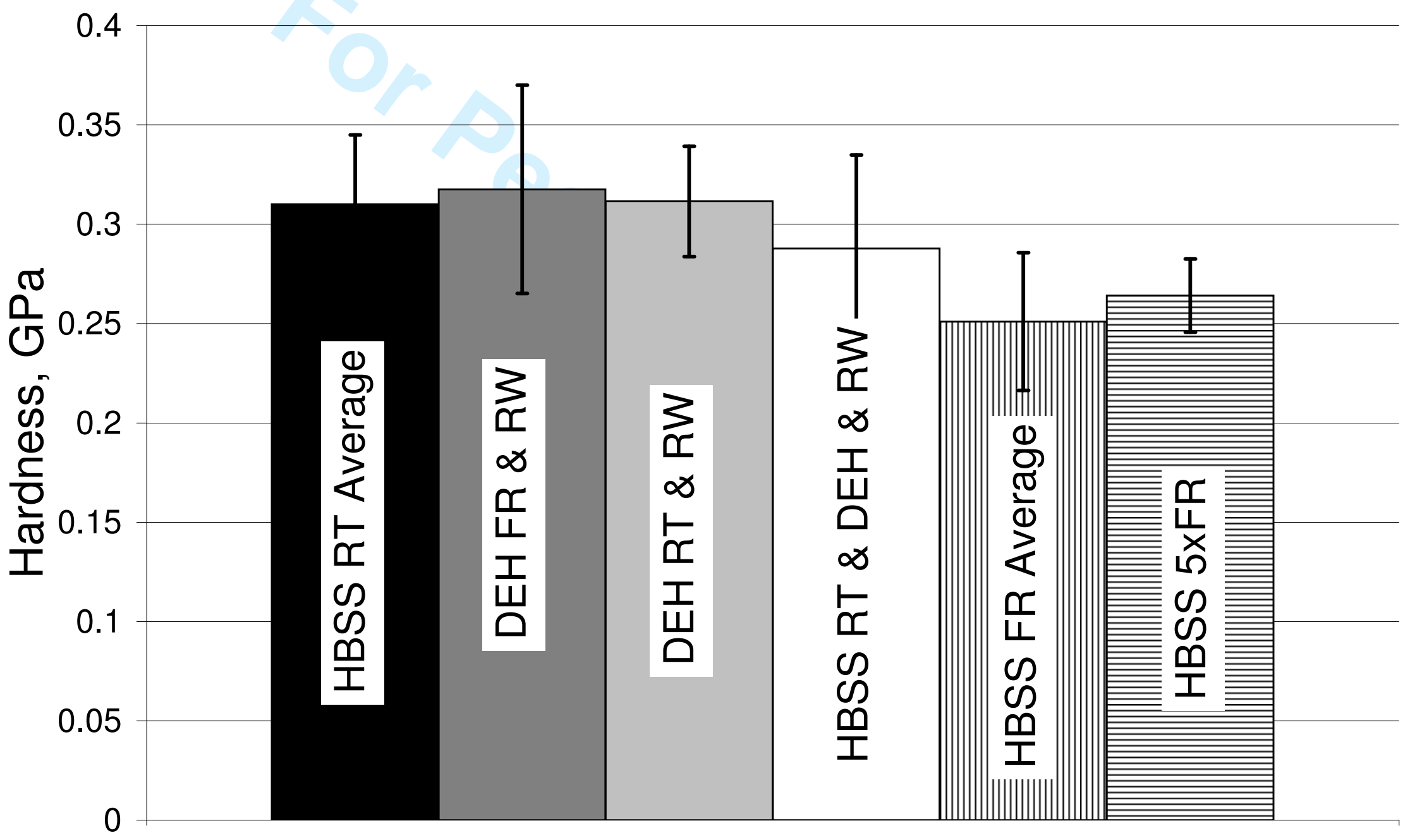




\section{TABLES}

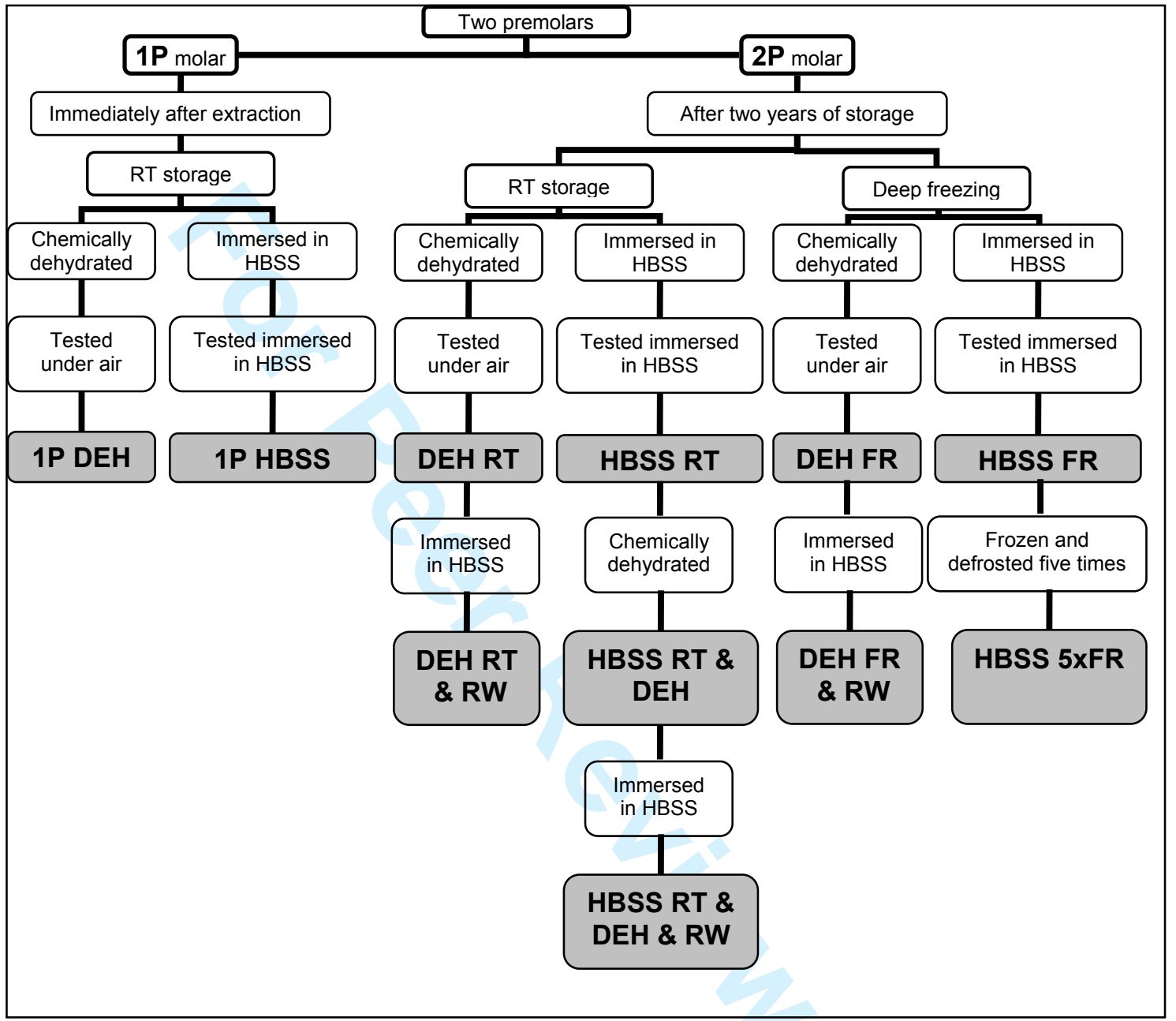

Table 1. Schema showing all the experimental conditions used (in white boxes) and the nomenclature chosen (grey boxes).

\begin{tabular}{|l|l|l|c|c|}
\hline Sample & \multicolumn{2}{|l|}{ Condition } & Hardness, H (GPa) & Elastic Modulus, E (GPa) \\
\hline \multirow{2}{*}{$1 \mathrm{P}$} & HBSS & $0.30 \pm 0.05$ & $14 \pm 2$ \\
\cline { 2 - 5 } & DEH & $0.92 \pm 0.12$ & $22 \pm 2$ \\
\hline \multirow{3}{*}{$2 \mathrm{P}$} & \multirow{2}{*}{ HBSS } & RT & $0.31 \pm 0.03$ & $12 \pm 2$ \\
\cline { 2 - 4 } & & FR & $0.25 \pm 0.03$ & $9 \pm 1$ \\
\cline { 2 - 4 } & \multicolumn{2}{|l|}{ DEH RT \& FR } & $0.96 \pm 0.07$ & $23 \pm 2$ \\
\hline
\end{tabular}

Table 2. Local mechanical properties of the initial tested conditions of both $1 \mathrm{P}$ and $2 \mathrm{P}$ samples. 


\section{CAPTIONS}

\section{FIGURES}

Fig.1. Each column represents the averaged elastic modulus $(E)$ and hardness $(H)$ of the $1 \mathrm{P}$ sample, both in the dry and wet condition. $\mathrm{E}$ is presented in Fig $\mathbf{1 a}$ and $\mathrm{H}$ in Fig $\mathbf{1 b}$. The difference in absolute values between both conditions can clearly be seen.

Fig.2. Elastic modulus (E) and Hardness (H) of $1 \mathrm{P}$ sample are shown in Fig 2a and Fig $\mathbf{2 b}$, respectively. In both graphs, left side of the figure corresponds to enamel, right side to intertubular dentin. Each point is a single measurement.

Fig.3. Elastic Moduli of all the tested WET conditions of 2P samples are shown in Fig $3 \mathrm{a}$. On the other hand, hardness data of all the tested WET conditions of 2P samples are plotted in Fig 3b. Columns values are average values. The error bars were calculated as the standard deviation (SD) of the measurements. HBSS RT and FR average are the average during the two week of testing of eac $h$ of the conditions, respectively. 


\section{FIGURES}

\section{Figure 1a}

\section{ELASTIC MODULUS}

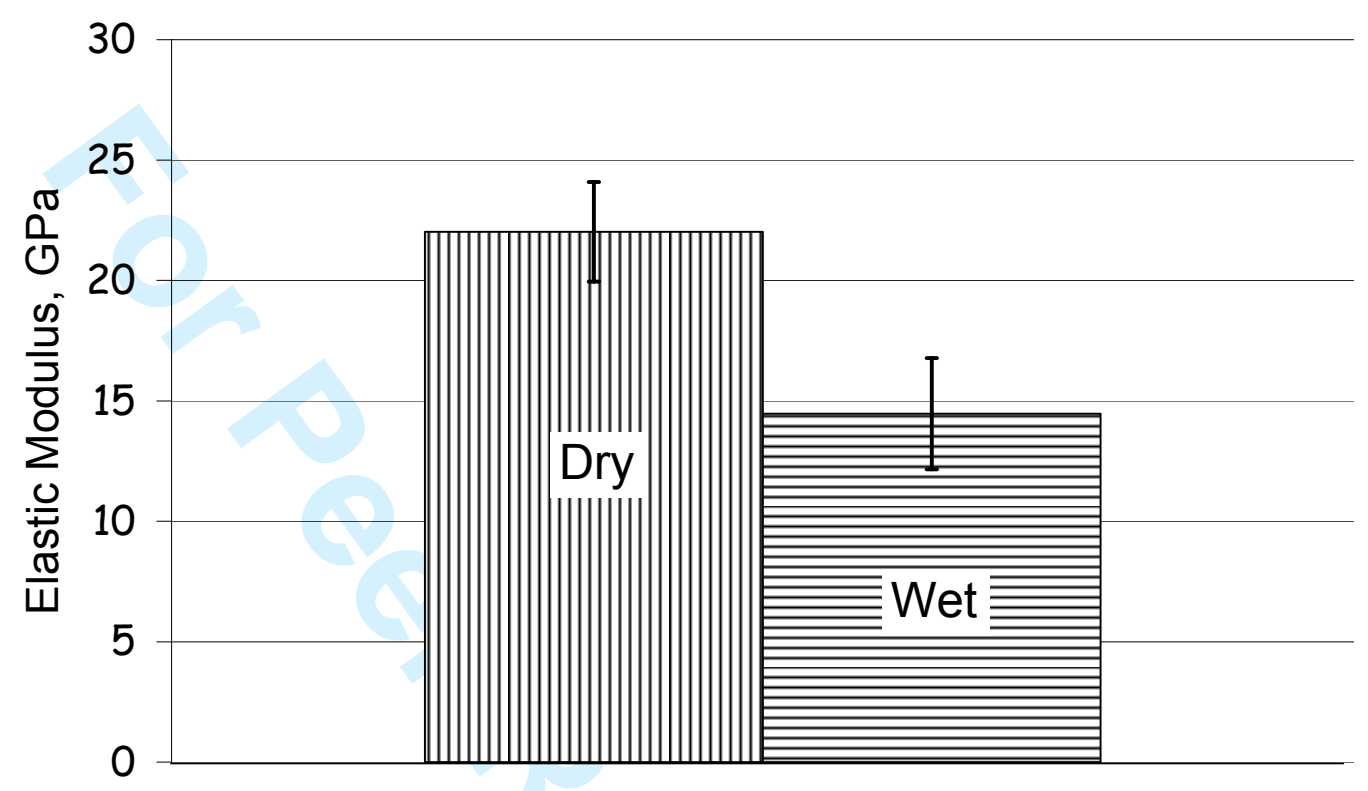

Figure $1 b$

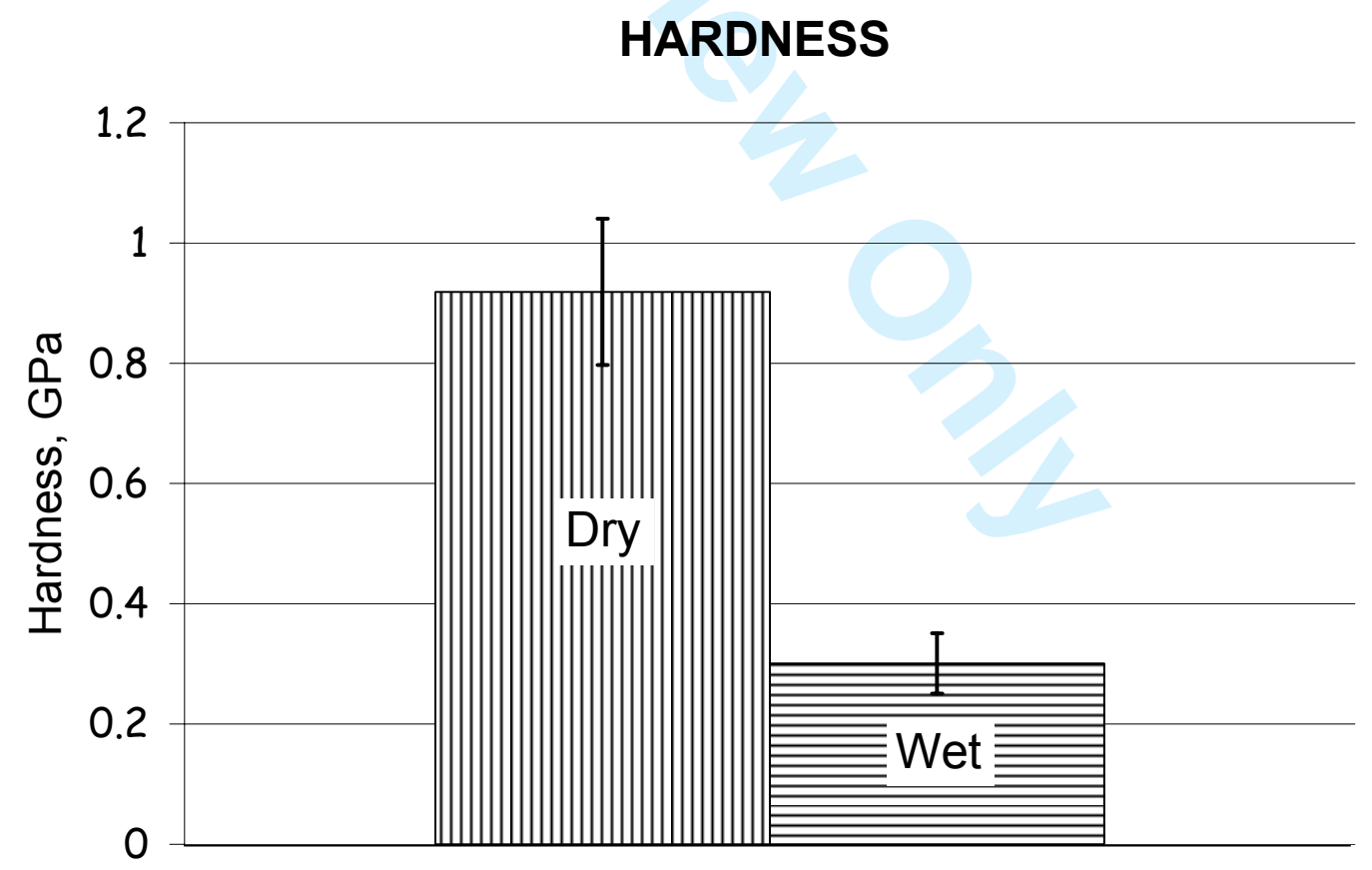




\section{Figure $2 a$}

\section{ELASTIC MODULUS}

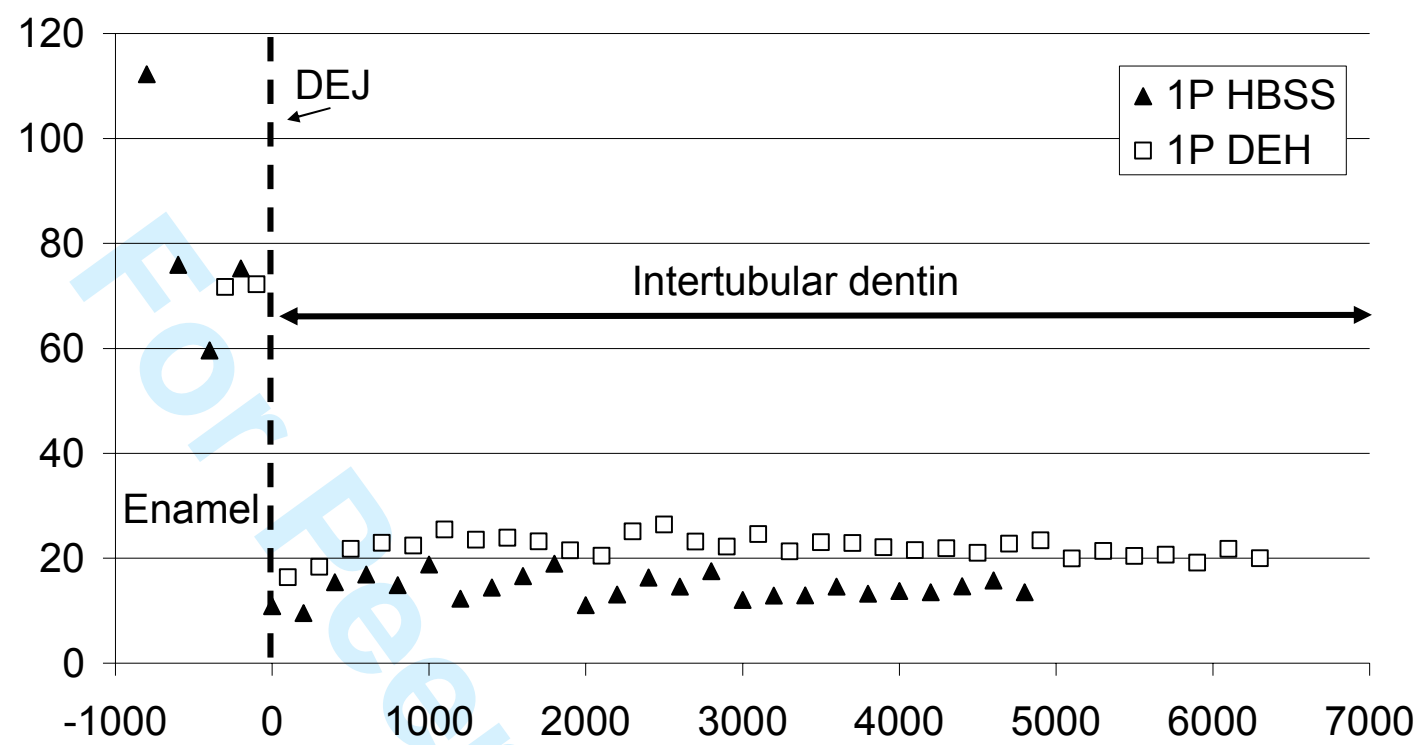

Figure $2 b$

\section{HARDNESS}

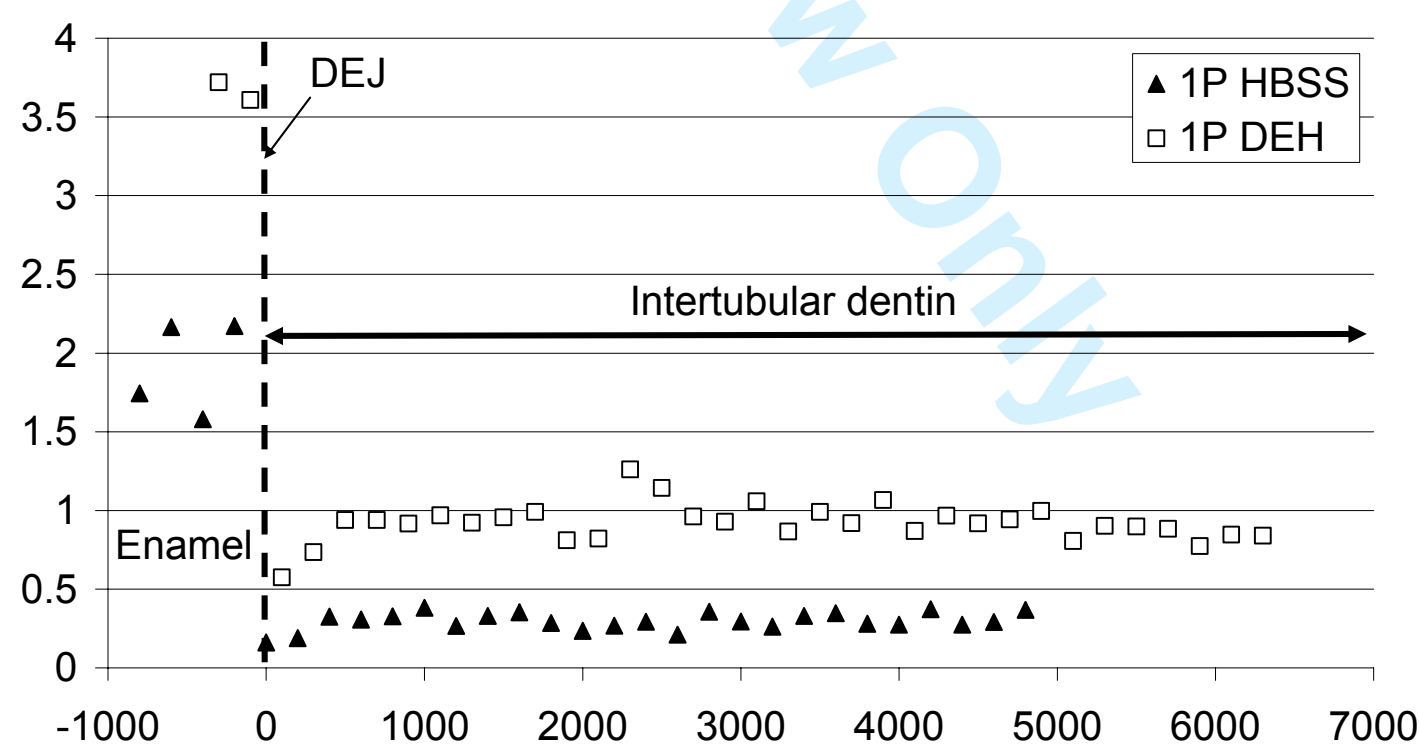




\section{Figure 3a}

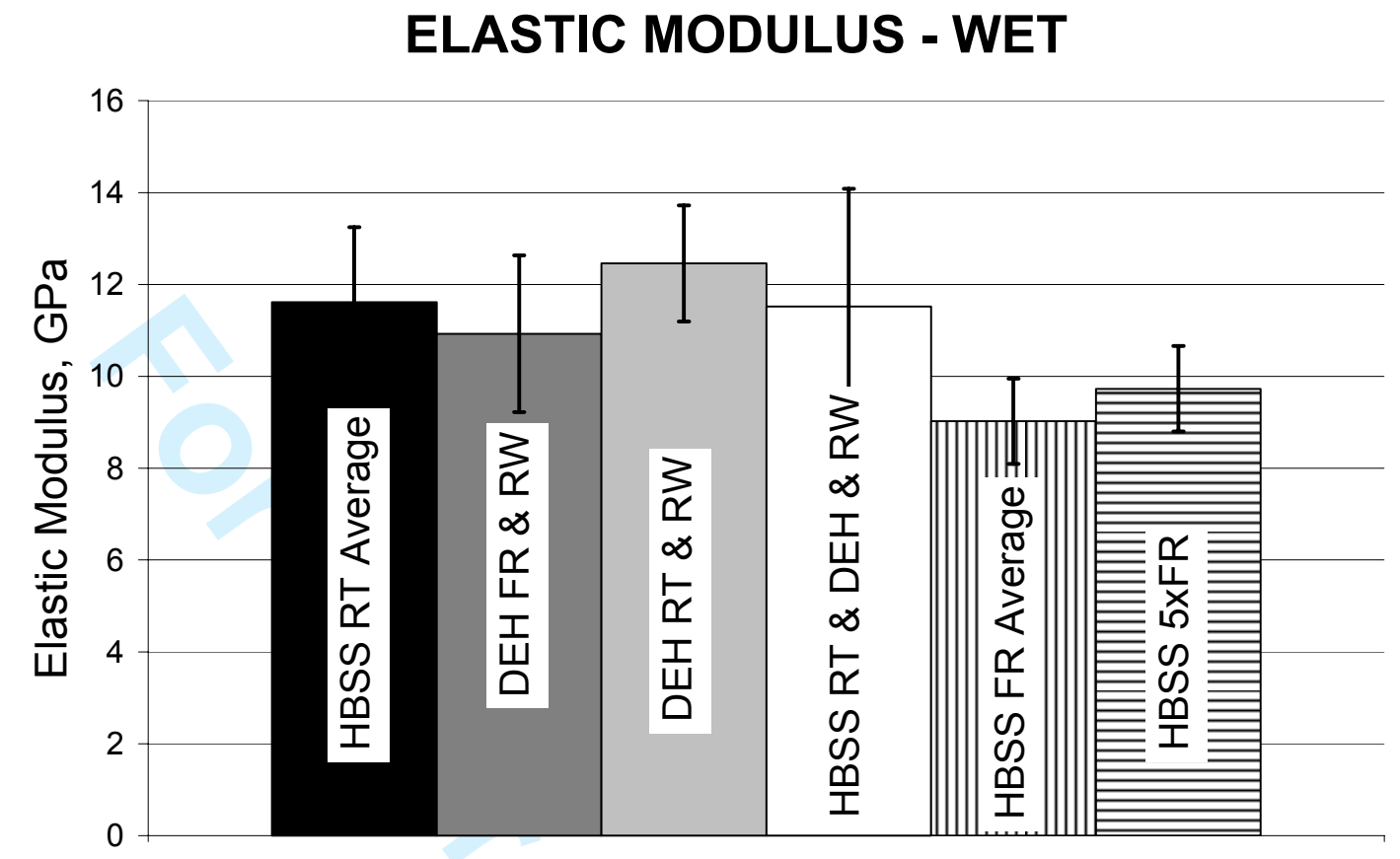

Figure $3 b$

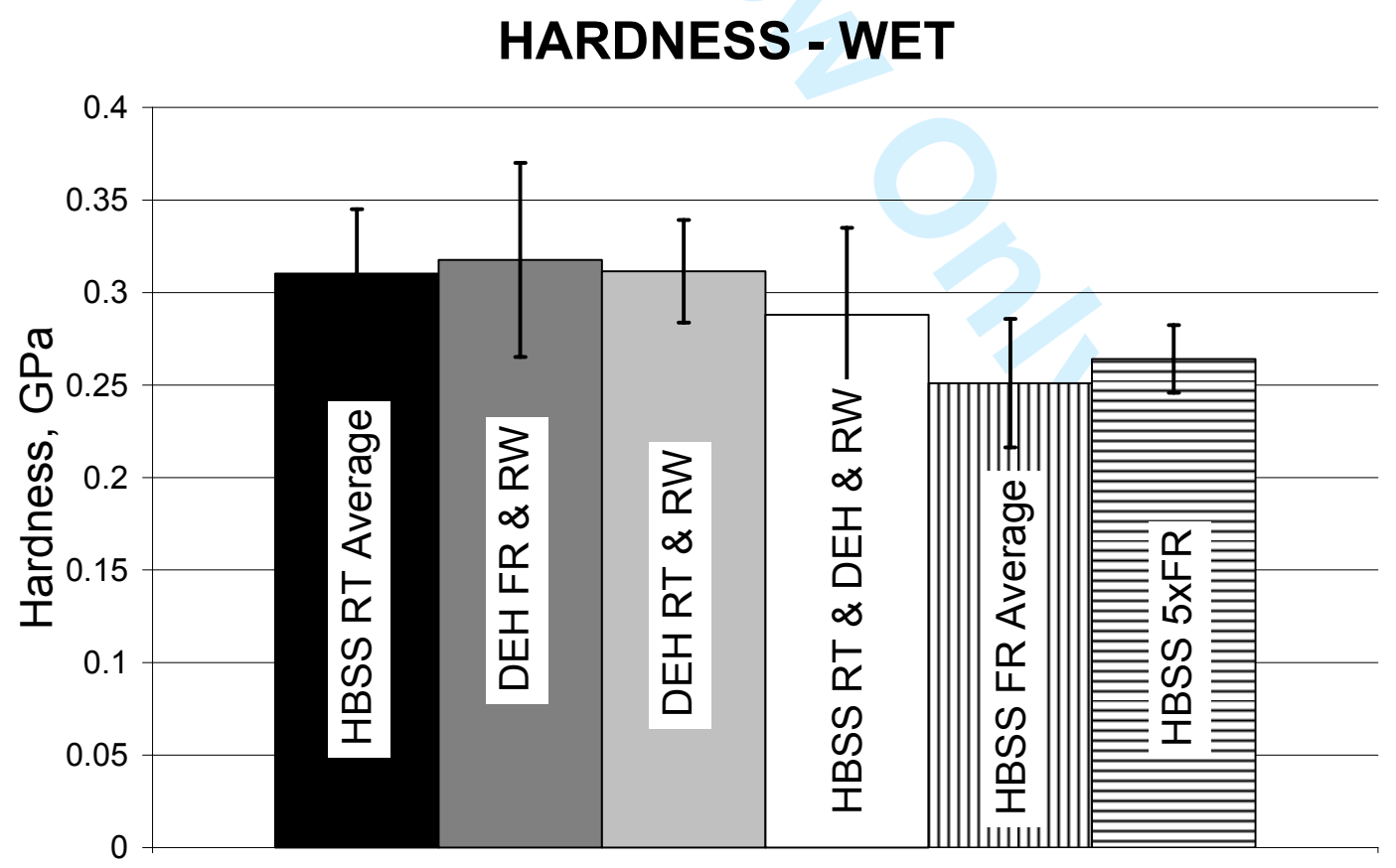

